\title{
A Pragmatic Study on English Teachers' Speech Acts in Universities
}

\author{
Ying Shi \\ School of Foreign Studies, Xi'an University, Xi'an, China \\ 395475480@qq.com
}

Keywords: English teachers; Speech acts; English class; Teaching efficiency

\begin{abstract}
The high quality teachers' speech acts can effectively impart knowledge, organize the classroom, give demonstrations and make English teaching efficient. Based on speech act theory, the paper tries to analyze teachers' directives, teachers' questions and teachers' feedbacks. The teachers and students of five universities are the subjects, and naturalistic observation and conversation analysis method are used in this study. Some significant conclusions from the paper are expected to meliorate teachers' teaching methods, so as to increase teaching efficiency.
\end{abstract}

\section{The Current Situation and Significance of the Study}

Teacher's speech acts is not only the medium of teaching, but also the reflection of teaching process. The high quality teachers' speech acts can effectively impart teaching contents, give demonstrations, accomplish teaching tasks and organize the classroom. According to speech act theory, a speaker might be performing three acts simultaneously when speaking: locutionary act, illocutionary act, and perlocutionary act. Speech act theory is an important theory in the pragmatic study of language. It was originated from the British philosopher John Austin in the late 50's of the 20th century. The significance of this study lies in enlarging teachers' linguistic knowledge, helping teachers to regulate their professional language and increasing teaching efficiency. The research of the teachers' speech acts in universities is very meaningful.

\section{Analysis of English Teachers' Speech Acts in Class}

This study mainly analyzes from three aspects: teachers' directive, teachers' questioning and teachers' feedback. The teachers and students from five Universities are the subjects. The English teachers' classroom recording was collected as the data. And naturalistic observation and conversation analysis are the research methods in this study.

English Teachers' Directives. Teachers give students opportunities to communicate with target language, invoke students' interest in the second language learning and organize classes' activities in the right way by teachers' directives. Basic sentence types are three kinds: declarative sentences, imperative sentences and interrogatives sentence.

Declarative sentences are often used to organize the classroom and presentation, which are used for teachers to express their views. For example"Excuse me", "Be quiet". Imperative sentences are main expression form of the directives. For example "Turn to page 8", "Let's learn new phrases". The teacher does not mention "you", because the students know the object of receive the directives are themselves in the English class when the teacher uses the directives. Teachers often use the "let's..." structure sentence to make the command simple and powerful. But the imperative tone is a little strong, it is easy to make students feel nervous. Teachers are advised to use the medium intensity direct directives such as "let's..." structure and add "please", which weakens the intensity of the illocutionary force in direct directives.

Comparing with imperative sentence, the interrogative sentences are more polite, more easily to be accepted by students. For example"Would you..., Could you...". Interrogative sentences are needed for teachers as a basic way to improve students' autonomy and creativity. It can help students to build their self-confidence which has great significance in quality oriented education. "Wh-questions" and "yes/no question" usually appear in English class, and the teacher likes to adopt to stimulate the student's interest. The structure of "Model V $+\mathrm{S}+\mathrm{V}$ " used to express the 
request, so it is usually used to express the teacher's wishes in the classroom. The tag-question has the function of emphasizing. The students can give a short and clear answer for optional questions.

Illocutionary acts of directives are mainly command, and teachers express their intentions directly. Perlocutionary acts are to let students accept these command quickly and directly, and follow the teacher's command to finish the tasks. Students follow the teachers' directives. The perlocutionary act is the real purpose of directives.

English Teachers' Questions. The types of questions are classified according to different standards. Here are some typical categories: on the basis of knowing the question's answer, the questions raised can be divided into display questions and referential questions; on the basis of not knowing the answers, they can be divided into close-ended questions and open-ended questions.

For example: What can you infer from this paragraph?

This open-ended question is a good referential question. Different students may have different answers to the same question. Therefore, it is better to use the referential questions with high quality than the simple display questions.

According to the theory of speech act, each question has its locutionary act, illocutionary act and perlocutionary act. The locutionary act refers to the content of the question on this basis. The illocutionary act means every question is the teacher's intention, they are five categories: commissives, assertives, directives, expressives and declarations(Searle 2001). The perlocutionary act refers to the teacher will get the answer of students. Questions can increase students'language output in class, improve their ability of thinking in English and master this language. From the perspective of speech act theory, the question itself is in the implementation of locutionary act, illocutionary act is to inspect and enlighten, and finally perlocutionary act is to promote the goal of language learning. The teachers should use variety of questions and make questions be the core of classroom teaching.

Searle' announced that all the questions are directives. But if change a way to ask questions, it may be gentler and more likely to be accepted for students. Illocutionary acts of questions can shift to locutionary acts questions or perlocutionary acts questions, thereby their effects to students may also be changed.

For example: Now, I'll give you 5 minutes to discuss how to make up the role play. No Chinese, understand?

The illocutionary act of this question means the teacher tells the students that they should finish this task in 5 minutes. The teacher can also ask in another way: We will do a role paly, can you get ready in 5 minutes? The exact mean of these two sentences is the same, but we can know that the indirect method is easier to be accepted than the direct one.

But sometimes the illocutionary act can also change to the perlocutionary act. For example: How did your role play like? Show us.

In this example, the first sentence of the illocutionary act is a request that the teacher attempts to make the students to do something. In this instance, the teacher makes an order to the students. The students have to do the role play whether they like it or not. If the teacher asks in another way, "Could you please make dialogues with your partner and show us?" In this case, the illocutionary act is the teacher's request for help, so that students can be respected by teachers. We can find that even if there is no change of illocutionary act, the perlocutionary act is changed after the questions have changed.

English Teachers' Feedbacks. According to the speech act theory, effective feedbacks can stimulate students' interest and motivation. It can be classified into two kinds: positive feedbacks and negative feedbacks. Feedbacks are locutionary acts and illocutionary acts, and the perlocutionary acts is the effects of feedbacks to the students. In the teaching process, different teachers' feedbacks have different illocutionary act. The general praises are assertive, such as"well done" "great".

English teachers' classroom feedback itself is locutionary act, and the praise, criticism or error correction performance to the students'answers is illocutionary act. Perlocutionary act is reflected in the students' mental, emotional and the different effects of learning. Here are some examples to 
show that what the high quality feedback is.

Question: What can you do on Sundays?

S: We can go shopping with friends.

T: Very good.

S: We can wash clothes.

T: Yes, we can.

S: We can go outside.

T: You mean stroll, yes? Ok. That's right.

At first, the teacher gives positive feedback to confirm the student's answer, and then repeat the answer to show the main idea of the students. Such these feedbacks make students feel valued when they answer this question. So the teacher gave the students not only knowledge, but also confidence. As we all know, high quality feedbacks are not always used in the teaching process and low quality feedbacks are everywhere. For example:

Feedback 1: Ok, sit down. This is a typical feedback. It's short without any repetition or comment, even doesn't tell the student whether his / her answer is correct. This kind of feedbacks is a directive that the teacher tries to finish the classroom tasks as soon as possible. Teachers had better change the feedbacks into other types, such as repetition and praise, correction of errors directly, or guide students to correct answers. And from the accurate feedback, the perlocutionary act changes from confusing to understanding the good or bad of their answers.

Feedback 2: Ok, Listen to my question earnestly, I'll ask you next time. The illocutionary act of this feedback is an order and commitment. The teacher asked the students to prepare questions and answer the questions next time. The teacher was not pleased because the student didn't answer the question exactly right. If the teacher gives the feedback in this way: I would be grateful if you could think about my question earnestly next time. The illocutionary act of this feedback changed from an expressive to a directive, and the perlocutionary act can encourage the student.

Feedback 3: Nearly correct, but you'd better...Positive feedbacks make students feel valued when they are answering questions. Negative feedback is inevitable in class. If teachers can't avoid using negative feedback, the indirect negative feedbacks may be a good choice. Teachers can use the subjunctive mood. For example: if you prepare very well now, your answer will be better. Or you can use incomplete negation: your answer is great except for some pronunciation problems. As a kind of speech act, teachers' feedback aims to obtain various pragmatic function. High quality feedbacks will have positive influence to students and low quality feedbacks will have negative influence. Teachers' positive feedback can stimulate students' learning motivation and improve their confidence. According to the study, we can know positive feedback can let students understand that they have completed their tasks, and why their answers are great.

\section{Implication}

According to the speech act theory, there are two types of directives: direct directives and indirect directives. Direct directives are very clear, they can make the students understand the command immediately; for indirect directives, illocutionary acts are doubt or request, and the teacher's purpose is to express indirectly. English teachers should guide teaching based on speech act theory. Every teacher has the responsibility to improve their professional knowledge to provide accurate directives. In English teaching, the standard and the appropriate directives can not only provide students with high level language input, but also help to improve the teaching quality.

Teachers' questions also play an important role in English teaching. And they help teachers to make sure that whether students understand the content of the course. However, at the present, we know that the teacher's questions are mainly display questions. More referential questions should be used in English teaching process. Students should get more opportunities to express themselves.

From the study of teacher's feedback, the praise feedback was used frequently, however, in fact, they can not provide students enough knowledge. According to the results of the study, we can know whether the teaching task is completed through the feedbacks, teachers give feedback not only by repeating the answer, but also by evaluating the advantages and disadvantages of the 
students' answers so that the students can understand the problem better and participate in classroom interaction more actively.

In college English teaching, pragmatic theory plays an important guiding role. English teachers should use this theory properly to instruct their classroom teaching, and focus on the role of teachers' speech acts in classroom activities, thus to increase teaching efficiency.

\section{Acknowledgements}

This reasearch is sponsored by State Minstry of Education (17XJA740001) and Xi'an University Fund Project for curriculum reform (JG2017002).

\section{References}

[1] Nunan, D. Language Teaching Methodology: A Textbook for Teachers. Englewood Cliffs, NJ: Prentice Hall Inc. (1991)

[2] Austin J L. How to Do Thing with Words. Beijing: Foreign Language Teaching and Research Press \& Cambridge University Press. (2002)

[3] Searle J. Speech Acts - An Essay in the Philosophy of Language. Cambridge University Press. (2001)

[4] Levinson, S.C. Pragmatics. Cambridge University Press.(2001)

[5] Leech G. Principles of Pragmatics. London: Longman. (1998)

[6] Wittrock. Handbook of Research on Teaching. New York: Macmillan Publishing Company.(1986)

[7] Walsh J. How to Teach English. Beijing: Foreign Language Teaching and Researching Press.(2002)

[8] Chaudron C. Second Language Classroom: Research on Teaching and Learning. Cambridge: Cambridge University Press.(1988)

[9] Thornbury S. Teachers Research Teacher Talk. ELT Journal. (1996)

[10] Searle.J.R. The classification of Illocutionary Acts. Language in Society, 5, 1-24.(1976)

[11]Searle.J.R. Speech Acts. Cambridge: Cambridge University Press.(1969) 